\title{
A Tale of 2 Medications: A Desperate Race for Hope
}

Microbe hunting is a story of amazing stupidities, fine intuitions, insane paradoxes.

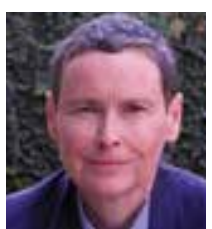

Cynthia M.A. Geppert, MD, Editor-in-Chief Correspondence: Cynthia Geppert (ethicdoc@ comcast.net)
$F$ or health care professionals, especially those in the epicenters of the pandemic, among the most distressing aspects of this first wave of COVID-19 has been the absence of any drug to treat the virus. The practitioners on the frontlines have confronted repeated surges of critically ill and dying patients without any effective treatment to offer, resulting in feelings of hopelessness, guilt, moral distress, depression, and in some tragic cases, suicide. ${ }^{2}$

On May 12th, the Centers of Disease Control and Prevention (CDC) released additional guidance on the antiviral medications that are the subject of this essay. The CDC may have updated its treatment guidelines in part to try and bring a measure of clinical reasoning and scientific order into the impassioned and politicized chaos that surrounded hydrocloroquine and remdesivir in the media. ${ }^{3}$

In this fourth installment of my series on pandemic ethics, we examine the desperate race for hope in the form of drug treatments for COVID-19. The race has been run faster than any in history thanks to biotechnology, genetic engineering, and artificial intelligence, although many experts believe it will still be a marathon rather than a sprint to a vaccine. ${ }^{4}$

The first editorial in this series provided a primer of the key differences between public health ethics and clinical ethics. Another crucial distinction is the far more pervasive and powerful influence of nonmedical factors in decision making, including political agendas, economic motives, journalistic hyperbole, and cultural biases and orientations. These competing interests make it even more challenging for scientists of integrity and health care institutions that are trying to uphold core values to make principled judgments about what is best for critically ill patients and the demoralized staff caring for them. In the remainder of this column, I will trace the dynamics of these forces as they im- pact the use of 2 drugs in federal practice: hydroxychloroquine and remdesivir.

The trajectory of hydroxychloroquine has been a political and medical roller-coaster since the pandemic hit, as is evident in its US Department of Veterans Affairs (VA) ride. Various media outlets have reported that beginning about March 26, 2020, VA placed orders for up to $\$ 400,000$ of the antimalarial drug hydroxychloroquine to be given to veterans hospitalized with COVID19. ${ }^{5}$ The same day the VA Office of Inspector General (OIG) issued a report critical of VA pandemic readiness and its availability of hydroxychloroquine. ${ }^{6}$

The VA strongly refuted the report, objecting to the premise of the OIG investigation, which was to determine whether VA facilities had on hand a 14-day supply of chloroquine or hydroxychloroquine. "This is both inaccurate and irresponsible." Noting that the drugs were still under investigation, the VA insisted that "No conclusions have been made on their effectiveness. To insist that a 14 days' supply of these drugs is appropriate or not appropriate displays this dangerous lack of expertise on COVID-19 and Pandemic response." 6

In April, National Institutes of Healthsponsored researchers released data that hydroxychloroquine actually increased mortality among VA patients with COVID-19, leading veterans' groups and the Senate minority leader to demand that VA cease to use hydroxychloroquine for COVID-19. ${ }^{8}$ As recently as May 15, the Associated Press reported that top VA officials have defended their use of the medication and stated they will not stop administering the medication for this indication. ${ }^{9}$ And VA is not alone, many other health care institutions are still prescribing hydroxychloroquine even amid scientific controversy about its putative benefits. In response to the growing awareness 
of the potential harms of the drug, the World Health Organization on May 25 announced it was halting all hydroxychloroquine trials. ${ }^{10}$ Why then do some physicians and health care providers continue to prescribe it? $\mathrm{Be}$ cause when nothing else stands between the patient and certain death even if there are known risks and uncertain benefits, some in health care feel morally obliged to use their best clinical judgment to help a patient.

Remdesivir's fortunes both scientific and monetary also rose and fell on the tide of mixed results from studies. Military Times reported on March 10, 2020, that the US Army Medical Research and Development Command had made an agreement with Gilead Sciences, the manufacturer of remdesivir, to provide the medication to COVID-19-positive service members. ${ }^{11}$ The antiviral had failed against Ebola and hepatitis but showed some efficacy for Middle East respiratory syndrome (MERS) and severe acute respiratory syndrome (SARS). On April 15, the Secretary of the Army announced that 2 COVID19-positive soldiers had recovered after being given remdesivir. ${ }^{12}$ In late April, the National Institute of Allergy and Infectious Diseases reported that in the scientific gold standard randomized placebo-controlled trial, remdesivir did speed the recovery of patients with advanced COVID-19. With the publication of the study in the prestigious New England Journal of Medicine on May 22, 2020, clearly the Army had bet on the right horse. ${ }^{13}$

This column has not been about quack cures and patent medicines that greed and ignorance breed in almost every American public health crisis-although these are by no means absent in this pandemic. This is about the serious endeavor of the top scientists and physicians in the country and, indeed, the world to discover a new medication or to repurpose an older pharmaceutical that is effective in the battle against COVID-19. The pressure on scientists and physicians to find a magic bullet in the battle against such an implacable enemy is unprecedented and unimaginable and can easily lead to sloppy science and ethical erosion.

In a utopia, pharmaceutical and vaccine research would be a matter of the discoveries of basic science trialed in the proof of concept of clinical care on a methodical, deliberate, and exacting timetable that balanced burdens and benefits.

In our current dystopia, science and medicine are only one of the many considerations affecting drug and vaccine development. As scientists and health care practitioners, we all experience a therapeutic imperative that we must heed with both caution and courage. Without caution we risk causing more harm than the disease we are fighting. Without courage we lose hope, the most potent antidote of all.

\section{Author disclosures}

The author reports no actual or potential conflicts of interest with regard to this article.

\section{Disclaimer}

The opinions expressed herein are those of the author and do not necessarily reflect those of Federal Practitioner, Frontline Medical Communications Inc., the US Government, or any of its agencies. This article may discuss unlabeled or investigational use of certain drugs. Please review the complete prescribing information for specific drugs or drug combinations-including indications, contraindications, warnings, and adverse effects-before administering pharmacologic therapy to patients.

\section{References}

1. de Kruif P. Microbe Hunters. San Diego, CA: Harcourt Brace Jovanavick; 1926.

2. Watkins A, Rothfeld M, Rashbaum WK, Rosenthal BM. Top ER doctor who treated patients dies by suicide. New York Times. April 27, 2020. https://www.nytimes.com/2020/04/27 /nyregion/new-york-city-doctor-suicide-coronavirus.html. Updated April 29, 2020. Accessed May 26, 2020.

3. National Institutes of Health. https://www.covid19treatmentguidelines.nih.gov/whats-new. Updated May 12, 2020. Accessed June 5, 2020.

4. Doheny K. Finish line unpredictable for COVID-19 vaccine race. https://www.webmd.com/lung/news/20200424/finish -line-unpredictable-for-covid-vaccine-race. Published April 29, 2020. Accessed May 26, 2020.

5. Horton A. What VA isn't saying about hydroxychloroquine-and everything else related to coronavirus. Washington Post. May 1, 2020. https://www.washingtonpost .com/national-security/2020/05/01/hydroxychloroquine -veterans-trump. Accessed May 27, 2020.

6. US Department of Veterans Affairs, Veterans Health Administration, Office of the Inspector General, Office of Healthcare Inspections. OIG inspection of Veterans Health Administration COVID-19 screening processes and pandemic readiness. https://www.va.gov/oig/pubs/NAOIG-20-02221-120.pdf. Published March 19-24, 2020. Accessed May 26, 2020.

7. Maganoli J, Narendran S, Pereira F, et al. Outcomes of hydroxychloroquine usage in United States veterans hospitalized with Covid-19 [preprint]. doi.org/10.1101/2020.04.16.20065920.

8. Yen H, Balsamo M. Schumer calls on VA to explain use of unproven drug on vets. Associated Press. May10, 2020. https://apnews.com/a2830445e55c6ea324e9a23e4c38f7c3. Accessed May 27, 2020.

9. Yen H. VA says it won't stop use of unproven drug on vets for now. Associated Press, May 15, 2020. https://apnews .com/2edd19decf58ed921d9b7ba9f6a2b44e. Accessed May $27,2020$.

10. World Health Organization. Coronavirus: WHO halts trials of hydroxychloroquine over safety fears. http://www.bbc.com 
/news/health-52799120. Accessed May 29, 2020.

11. Kime P. Army signs agreement with drug giant Gilead on experimental COVID-19 treatment. Military Times. March 10, 2020. https://www.militarytimes.com/news/your -military/2020/03/10/army-signs-agreement-with-drug -giant-gilead-on-experimental-covid-19-treatment. Accessed May 27, 2020.

12. Cox M. Two U.S. soldiers with Covid-19 'up and walking around' after taking Ebola drug. https://www.military.com /daily-news/2020/04/15/two-us-soldiers-covid-19-and -walking-around-after-taking-ebola-drug.html. Published April 15, 2020. Accessed May 27, 2020.

13. Beigel JH, Tomashek KM, Dodd LE, et al; ACTT-1 Study Group Members. Remdesivir for the treatment of COVID19-preliminary report. N Engl J Med. May 22, 2020. doi: 10.1056/NEJMoa2007764

\section{LETTERS}

\section{Microthrombotic Complications of COVID-19 Are Likely Due to Embolism of Circulating Endothelial Derived Ultralarge von Willebrand Factor (eULVWF) Decorated-Platelet Strings}

To the Editor: COVID-19 is a pandemic caused by the virus SARS-CoV-2. Serious complications of COVID-19 are characterized by acute respiratory distress syndrome (ARDS), pneumonia and rapidly progressing to multiorgan dysfunction syndrome (MODS).

The pathophysiology of COVID-19 is not fully understood yet and neither vaccine nor clearly effective antiviral treatment is available at this time. Based on the endothelial pathogenesis of viral sepsis, which includes ARDS as seen in severe acute respiratory syndrome (SARS) due to SARS-CoV and Middle East respiratory syndrome due to MERS-CoV, ${ }^{1,2}$ we believe COVID-19-associated ARDS is also caused by endotheliopathy-associated vascular microthrombotic disease (EA-VMTD), which also involves multiorgan dysfunction syndrome (MODS) that has been reported as the cause of death. ${ }^{3}$ We suspect these complications are secondary to disequilibrium state (for various reasons ${ }^{4,5}$ ) between insufficient ADAMTS13 and excessive exocytosis of ultra large von Willebrand factor multimers (ULVWF) from WeibelPalade bodies present in endothelial cells due to COVID-19-induced endotheliopathy.

Endothelial-derived ULVWF multimers anchored to the endothelial surface of the vascular wall recruit platelets and initiate microthrombogenesis within the microvasculature, leading to large microthrombi strings composed of platelet and eULVWF complexes like "beads-on-astring structures"6 where platelets firmly adhere to eULVWF, instead of roll on eULVWF strings. ${ }^{4}$ Platelets, once adhered to eULVWF strings, are rapidly activated causing platelet aggregation and also recruit leukocytes in a P-selectin dependent manner. ${ }^{4}$ These aggregates grow until they become sufficiently large and can no longer be held onto the eULVWF strings against the force of blood flow and released from endothelial cells into the circulation. ${ }^{4}$ It appears to us that in COVID-19 microthrombotic disease, large amounts of circulating complexes of endothelial-derived ULVWF decorated-platelet microthrombi strings are filtered in the microvasculature (embolism) or develops in the microvasculature in situ causing microthrombotic occlusion. During our data search, we have come across several articles published by Chang, including on endotheliopathy causing vascular microthrombotic disease based on a novel concept of "TTP-like syndrome"

The genesis of EA-VMTD in TTP like syndrome is suspected to be triggered by complement activation and terminal complement complex (C5b-9, membrane attack complex, MAC) may play a key role in producing endotheliopathy. ${ }^{7}$ Magro and colleagues reported that COVID-19 patients have demonstrated 
generalized thrombotic microvascular injury involving the lungs and skin showing intense complement activation and C5b-9 deposition in the tissue. ${ }^{8}$ Also, recent pathology reports of COVID-19 diseased lungs showed extensive platelet-rich clotting with adherent mononuclear cells and extensive fibrin clotting, ${ }^{9}$ which appear consistent with involvement of NETosis. ${ }^{10}$ In another case report from Switzerland, a patient with severe COVID-19 had massive elevation of VWF antigen and activity (555\% and 520\%, respectively) and increased Factor VIII clotting activity (369\%). ${ }^{11}$ These findings support vascular endotheliopathy causing exocytosis of ULVWF and associated increase in Factor VIII causing microthrombotic disease/embolism.

COVID-19 clinical syndrome appears very much consistent with EA-VMTD presenting with ARDS and MODS as well as micromacro-thrombotic complications, including peripheral ischemia/gangrene involving fingers and toes and skin necrosis., ${ }^{8,12}$

We believe that an appropriate therapy may not be anticoagulation but should include antimicrothrombotic therapy targeting endotheliopathy and primary hemostasis in the early stages of the disease (platelet adhesion, activation, and aggregation; especially eULVWF) like recombinant CD59 (membrane attack complex inhibition factor [MACIF]), recombinant ADAMTS13, glycoprotein IIb/IIIa receptor blocker, therapeutic plasma exchange, and perhaps anticomplement therapy (in selected cases) and others; these need to be validated in clinical trials prior to clinical application.

Of note, ADAMTS13 is a zinc containing protease. We noted that zinc and calcium concentrations play a significant role (in vitro) in ADAMTS13 activity in citrated plasma and recombinant ADAMTS13 activity with no added chelators (recombinant ADAMTS13 activity can enhance up to 200-fold); whereas in high zinc concentrations, ADAMTS13 gets deactivated. ${ }^{13}$ We suggest this finding merits an urgent clinical trial since it appears to us as the best possible cost-effective treatment for COVID-19 microthrombotic complications.

In this view of clinical pathophysiology of sepsis in COVID-19, we would like to en- lighten the relationship between endothelial pathogenesis of coronaviral sepsis and vascular microthrombotic disease and would urge the medical community to immediately explore appropriate therapeutic options.

\section{N. Varatharajah, MD Suganthi Rajah, MD Virginia, US}

Disclaimer: The opinions expressed herein are those of the authors and do not necessarily reflect those of Federal Practitioner, Frontline Medical Communications Inc., the US Government, or any of its agencies.

\section{References}

1. Chang JC. Sepsis and septic shock: endothelial molecular pathogenesis associated with vascular microthrombotic disease. Thromb J. 2019;17:10. Published 2019 May 30. doi:10.1186/s12959-019-0198-4

2. Chang JC. Acute respiratory distress syndrome as an organ phenotype of vascular microthrombotic disease: based on hemostatic theory and endothelial molecular pathogenesis. Clin Appl Thromb Hemost. 2019;25:1076029619887437. doi:10.1177/1076029619887437

3. Zaim S, Chong JH, Sankaranarayanan V, Harky A. COVID-19 and multi-organ response. Curr Probl Cardiol. 2020;100618. In press. doi:10.1016/j.cpcardiol.2020.100618

4. Bernardo A, Ball C, Nolasco L, Choi H, Moake JL, Dong JF. Platelets adhered to endothelial cell-bound ultra-large von Willebrand factor strings support leukocyte tethering and rolling under high shear stress. J Thromb Haemost. 2005;3(3):562-570. doi:10.1111/j.1538-7836.2005.01122.x

5. Mannucci PM, Canciani MT, Forza I, Lussana F, Lattuada A, Rossi E. Changes in health and disease of the metalloprotease that cleaves von Willebrand factor. Blood. 2001;98(9):2730-2735. doi:10.1182/blood.v98.9.2730

6. Dong JF, Moake JL, Nolasco L, et al. ADAMTS-13 rapidly cleaves newly secreted ultralarge von Willebrand factor multimers on the endothelial surface under flowing conditions. Blood. 2002;100(12):4033-4039. doi:10.1182/blood-2002-05-1401

7. Chang JC. TTP-like syndrome: novel concept and molecular pathogenesis of endotheliopathy-associated vascular microthrombotic disease. Thromb J. 2018;16:20. Published 2018 Aug 11. doi:10.1186/s12959-018-0174-4

8. Magro C, Mulvey JJ, Berlin D, et al. Complement associated microvascular injury and thrombosis in the pathogenesis of severe COVID-19 infection: a report of five cases. [Published online ahead of print, 2020 Apr 15.] Transl Res. 2020;S19315244(20)30070-0. doi:10.1016/j.trsl.2020.04.007

9. Guang Li, Sharon E. Fox, Brian Summa, et al. Multiscale 3-dimensional pathology findings of COVID-19 diseased lung using high-resolution cleared tissue microscopy. https:// www. biorxiv.org/content/10.1101/2020.04.11.037473v1. full.pdf. Posted April 20, 2020. Accessed May 14, 2020. doi: 10.1101/2020.04.11.037473

10. de Bont CM, Boelens WC, Pruijn GJM. NETosis, complement, and coagulation: a triangular relationship. Cell Mol Immunol. 2019;16(1):19-27. doi:10.1038/s41423-018-0024-0

11. Escher R, Breakey N, Lämmle B. Severe COVID-19 infection associated with endothelial activation. Thromb Res. 2020;190:62. doi:10.1016/j.thromres.2020.04.014

12. Landa N, Mendieta-Eckert M, Fonda-Pascual P, Aguirre T. Chilblain-like lesions on feet and hands during the COVID-19 Pandemic. Int J Dermatol. 2020;59(6):739-743. doi:10.1111/ijd.14937

13. Anderson PJ, Kokame K, Sadler JE. Zinc and calcium ions cooperatively modulate ADAMTS13 activity. J Biol Chem. 2006;281(2):850-857. doi:10.1074/jbc.M504540200 